\title{
KEMAMPUAN ZEOLIT ALAM DAN BATU APUNG DALAM MENURUNKAN KADAR KLORIDA PADA AIR PAYAU Syamsuddin $\mathbf{S}^{1}$ dan Yerlisa Beso ${ }^{2}$ \\ 1,2 Jurusan Kesehatan Lingkungan Poltekkes Kemenkes Makassar syam.kesling@gmail.com
}

\begin{abstract}
Clorida is an anion shaped sodium chloride that causes saltiness in clean water (well water). Chloride ions are one of the major inorganic anions found in natural waters in greater quantities than other halogen anions. This type of research is a quasi experiment aimed to find out the capability of zeolite and pumice stone media with different dose variation that is 180 $\mathrm{gr}, 190 \mathrm{gr}, 200 \mathrm{gr}$, in decreasing the chloride content in brackish water and to find out how big the decrease of chloride level in brackish water. The results of research that have been done by using media of zeolite and pumice stone with dose of 180 gr percentage decrease of cloride $42,98 \%$ and at dose $190 \mathrm{gr}$ average percentage decrease of cloride level $49,12 \%$, and at dose 200 gr average Percentage decrease of cloride level 54,16. Based on the results and discussion of the research, it was concluded that the treated water of zeolite and pumice cylinders with dose of $180 \mathrm{gr}, 190 \mathrm{gr}$, and $200 \mathrm{gr}$ can decrease the cloride level in brackish water but not yet fulfill the requirement based on Permenkes 416 of 1990. Therefore We as the authors suggest that the use of media zeolite and pumice stone should be used as an alternative to reduce levels of cloride in brackish water.
\end{abstract}

Keyword : Zeolite, Pumice, Chloride levels

\section{ABSTRAK}

Clorida merupakan anion berbentuk Natrium Korida yang menyebabkan rasa asin dalam air bersih (air sumur). Ion clorida adalah salah satu anion anorganik utama yang ditemukan pada perairan alami dalam jumlah yang lebih banyak daripada anion halogen lainnya. Jenis penelitian ini adalah eksperimen semu bertujuan untuk mengetahui kemampuan media saring zeolite dan batu apung dengan variasi dosis yang berbeda yaitu $180 \mathrm{gr}, 190 \mathrm{gr}, 200 \mathrm{gr}$,dalam menurunkan kadar clorida pada air payau dan untuk mengetahui seberapa besar penurunan kadar klorida pada air payau. Hasil penelitian yang telah dilakukan dengan menggunakan media zeolite dan batu apung adalah dengan dosis $180 \mathrm{gr}$ presentase penurunan kadar clorida $42,98 \%$ dan pada dosis $190 \mathrm{gr}$ rata-rata presentase penurunan kadar clorida 49,12 $\%$,serta pada dosis $200 \mathrm{gr}$ rata-rata presentase penurunan kadar clorida54,16\%. Berdasarkan hasil dan pembahasan penelitian di simpulkan bahwa air yang telah diberi perlakuan saringan zeolite dan batu apung dengan dosis $180 \mathrm{gr}, 190$ gr,dan 200 gr dapat menurunkan kadar clorida pada air payau akan tetapi belum memenuhi syarat berdasarkan Permenkes 416 Tahun 1990. Oleh karena itu kami sebagai penulis menyarankan agar penggunaan media zeolite dan batu apung sebaiknya digunakan sebagai alternative untuk menurunkan kadar clorida pada air payau.

Kata Kunci : Zeolit, Batu Apung, Kadar Klorida

\section{PENDAHULUAN}

Air sebagai sumber daya alam yang diperlukan untuk kebutuhan hidup orang banyak, bahkan oleh semua makhluk hidup. Organisasi Kesehatan Dunia (WHO) kebutuhan air untuk daerah pedesaan 60 liter/orang/hari. Menurut penelitian Lesmana tahun 2003 telah melakukan uji efektifitas repelensi ekstrak sepuluh tanaman terhadap kecoak jenis Blatella germanica. Kesepuluh tanaman tersebut antara lain jeringau, kapulaga, serai dapur, F.vulgare, lawang, Lantana camara L, pandan, sirih, nilam dan akar wangi pada konsentrasi $0 \%, 1 \%$, dan $5 \%$ yang semuanya bersifat reppelent terhadap Blatella germanica.

Penyediaan air bersih untuk masyarakat mempunyai peranan yang sangat penting dalam meningkatkan kesehatan, yakni peranan dalam menurunkan angka penderita penyakit, khususnya yang berhubungan dengan air, dan berperan dalam meningkatkan standar atau taraf/kualitas hidup masyarakat.

\section{Tempat Penelitian}

Sampel air sumur diperoleh dari daerah pesisir pantai tanjung bayang, kelurahan Barombong, Kecamatan Tamalate kota makassar. Sedangkan pengolahan dan dianalisis di laboratorium Jurusan Kesehatan Lingkungan Poltekkes Makassar.

\section{Waktu Penelitian}

Waktu penelitian di bagi menjadi dua bagian :

a.Tahap pertama adalah persiapan, meliputi penentuan judul penyusunan proposal penelitian selama bulan januari 2017 februari 2017.

b.Tahap kedua meliputi kegiatan penelitian yang pemeriksaannya dilaksanakan di Laboratorium Politenik Kesehatan Makassar Jurusan Kesehatan Lingkungan yang berlangsung pada bulan April - juni 2017. 
Jurnal Sulolipu : Media Komunikasi Sivitas Akademika dan Masyarakat

Vol. 17 No.II 2017

e-issn : 2622-6960, p-issn : 0854-624X

\section{Variabel Penelitian}

Pada penelitian ini mencakup dua variable penelitian yaitu variabel bebas, variabel terikat dan variabel pengganggu.

\section{a. Variabel Bebas}

Variabel bebas dalam peneitian ini adalah zeolite alam dan batu apung dengan variasi dosis (180 gr, $190 \mathrm{gr}, 200 \mathrm{gr}$ ), berat bahan ditentutakan untuk mengetaui kempuan daya adsorbs bahan yang terjadi pada saat pengolahan dengan variasi dosis maka peneliti dapat mengetahui dosis bahan yan lebih efekif dalam proses pengolahan ini.

b. Variabel Terikat

Dalam Variabel terikat menjadi titik focus dalam peneitian ini adalalah Clorida (Cl), dengan kemampuan zeolite alam dan batu apung dalam menurunkan kadar clorida (Cl) dalam air payau/asin.

c. Variabel pengganggu

Adalah yang mempengaruhi variabel bebas dan terikat dalam hal ini suhu, kekeruhan,ukuran partikel,porositasi dan tekanan.

\section{Definisi Operasional}

a. Zeolit alam yang bersifat kation dalam penelitian ini adalah senyawa alumino-silikat hidratdengan rumus umum (LaAlbAic O2 $\mathrm{nH} 2 \mathrm{O}$ ), dengan diameter $0,5-1,5 \mathrm{~cm}$.

b. Batu apung adalah jenis batuan yang berpori serta mengandung mineral dan bahan kimia yang mampu bereaksi dengan corida $(\mathrm{Cl})$.

c. Zeolit aktif merupakan senyawa aluminosiikat hidrat teridrasi dengan unsur utama yang teridiri dari kation alkali dan alkali tanah terutama $\mathrm{Ca}, \mathrm{K}$ dan $\mathrm{Na}$ yang telah mengalami serangkaian proses pengaktifan dengan cara direndam $\mathrm{NaOH} 0,5 \mathrm{~N}$ selama 4 jam.

d. Adorbsi adalah metode yang digunakan untuk memisakan ion yang tidak dikehendaki berada dalam larutan,utuk dipindahkan kedalam media padat yang disebut dengan media penukar ion,dimana media penukar ion ini melepas ion lain kedalam larutan.

e. Kadar clorida adalah kadar ion yang terlarut dalam sampel air payau/asin yang dinyatakan dalam satuan $\mathrm{mg} / \mathrm{l}$.

f. Waktu kontak dalam penelitian ini adalah waktu yang dibutuhkan oleh sampel air untuk kontak dengan media,dan dinyatakan dalam satuan menit serta diukur dengan stopwatch,dalam waktu 15 menit.

g. $\mathrm{pH}$ (Power Hydrogen) Adalah sifat asam atau basa dar air payau yang ada di tanjung bayang, kelurahan barombong, kecematan tamalate kota makassar.

h. Suhu adalah derajat panas dingin air payau yang ada di tanjung bayang, kelurahan barombong, kecematan tamalate kota makassar.

i. Koagulan adalah zat kimia yang menyebabkan destabilisasi muatan negatif partikel di dalam suspensi.

j. Dalam kamus besar bahasa Indonesia (KBBI) definisi koagulasi adalah suatu kata yang berhubungan dengan keadaan atau perihal menjadi keras atau padat, baik secara keseluruhan ataupun sebagian cairan sebagai akibat dari perubahan kimiawi.

\section{Kriteria Objektif}

a. Zeolit alam dan batu apung dinyatakan mampu menurunkan kadar clorida (Cl) apabila kadar clorida air hasil pengolahan mengalami penurunan dari kadar awal dan memenuhi syarat yaitu $250 \mathrm{gr}$ sesuai dengan permenkes RI.No.416/MENKES/PER/IX1990

b. Zeolit alam dan batu apung dinyatakan tidak mampu menurunkan kadar clorida (Cl) apabila kadar clorida air hasil pengolahan tidak mengalami penurunan dengan metode koagulasi.

\section{Desain Penelitian dan prosedur kerja}

\section{a. DesainPenelitian}

Setelah dilakukan penelitian mengenai kemampuan batu apung dan zeolit alam maka dalam pembaasan ini ditunjukan pada analisis deskriptif yaitu.

\section{b. Prosedur kerja}

Tahap I (Pengaktifan bahan)

1) Siapkan alat dan bahan yang akan di gunakan

2) Batu apung dan zeolite di keringkan terlebih dahulu, setelah itu batu apung dan zeolite tersebut di hancurkan sampai membentuk serbuk.Batu apung dan zeolite yang telah di pilih di cuci dengan Auadesh 
3) Aktivasi pemanasan dengan

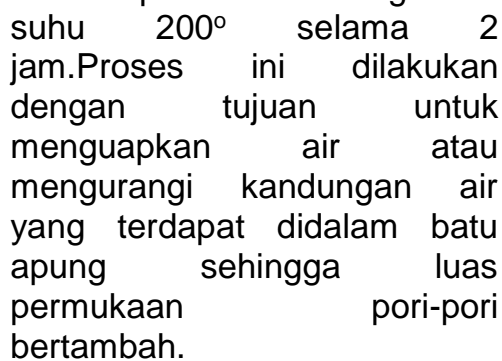

Tahapan II (Analisa Kadar Klorida Sampel)

Sampel yang akan di olah terlebih dahulu di periksa kandungan Cloridanya agar dapat di ketahui presentase penurunannya.

Tahapan III ( Proses Pengolahan)

Pada peneitian ini menggunakan skala kecil yaitu adorbsi pada sejumlah air dengan bahan yang akan digunakan pada keadaan tidak ada aliran masuk dan keluar (system bath dalam sejumlah beaker gelas).

1) Siapkan beaker gelas dengan ukuran 1 liter,masing-masing di isi dengan air sampel $500 \mathrm{ml}$.

2) Masukkan masing-masing bahan kedalam sampel air payau,dengan variasi berat 180 gr , $190 \mathrm{gr}, 200 \mathrm{gr}$.

3) Diaduk dengan pengadukan cepat pada putaran $100 \mathrm{rpm}$ selama 120 menit dengan metode koagulasi.

4) Diamkan selama 15 menit

5) Diadakan penyaringan kemudian beningnya dipindahkan ke botol sampel untuk di periksa kadar Cloridanya.

Tahapan ke IV ( Pemeriksaan Clorida Sampel )

1) Ukur sampel sebanyak $50 \mathrm{~m}$ kemudian atur Phnya hingga mencapai $\mathrm{pH} 7$ dengan menambahkan $\mathrm{NaOH} 1 \mathrm{~N}$ atau $\mathrm{H} 2 \mathrm{SO} 4$ masukan dala ernlenmeyer

2) Tambahkan larutan penunjuk $\mathrm{K} 2 \mathrm{CrO} 4$ sebanyak $1 \mathrm{ml}$

3) Titrasi dengan larutan $\mathrm{AgNO} 30,0141$ sampai warna merah bata

4) Catat skala penurunan pada burat dan hitung banyaknya $\mathrm{AgNO}_{3}$ yang di gunakan (misalnya $=$ Aml)

5) Untuk blanko ukur $50 \mathrm{ml}$ Auadesh masukkan dalam Erlenmeyer

6) Tambahkan $1 \mathrm{ml}$ larutan penunjuk $\mathrm{K} 2 \mathrm{CrO} 4$

7) Titrasi dengan $\mathrm{AgNO} 3$ sampai timbul warna merah bata
8) Catat skala pada burat dan hitung banyaknya $\mathrm{ml} \mathrm{AgNO3}$ yang di gunakan (misalnya $=\mathrm{B} \mathrm{ml}$ )

9) Cara Perhitungan

Clorida $=(\mathrm{A}-\mathrm{B}) \times \mathrm{N}$

AgNO3 $335,45 \times 1000=\ldots \ldots . . \mathrm{mg} / \mathrm{l}$

$\mathrm{ml}$ contoh

\section{Populasi Dan Sampel \\ Populasi}

Populasi adalah semua air gali sumur gali yang berada di kawasan pesisir yang di gunakan masyarakat sebagai sumber air bersih.

\section{Sampel}

Sampel air sumur gali yang memiiki kandungan kadar corida tertinggi di tanjung bayang.Pengambilan sampel diambil secara purposive dengan pertimbangan air sumur gali yang meiliki kadar clorida tinggi dengan tujuan pengolahan dengan menggunakan batu apung dan zeolite alam dengan variasi dosis $180 \mathrm{gr}, 190 \mathrm{gr}$, dan $200 \mathrm{gr}$.

\section{Teknik Pengumpulan Data}

Data Primer

Data primer merupakan data yang di kumpulkan melalui hasil analisa Laboratorium yang menegaskan hasil penelitian, dengan data ini penelitian dapat di ketauhui tingkat keberhasilan ataupun kemampuan zeolite dan batu apung dalam menurunkan kadar clorida dalam air payau.

\section{Data Sekunder}

Data sekuder merupakan data penunjang dalam penelitian ini,data tersebut dapat diperoleh dari data yang tersedia baik dari studi pustaka maupun penelitian sebelumnya yang berkaitan dengan penelitian tersebut.

\section{Pengolahan Dan Analisa Data}

Setelah dilakukan penelitian mengenai kemampuan batu apung dan zeolit alam maka dalam pembaasan ini ditunjukan pada analisis deskriptif yaitu kemampuan zeolite dan batu apung dalam menurunkan kadar corida pada air sumur gali (payau) di Tanjung Bayam Kota Makassar.

\section{HASIL PENELITIAN}

Berdasarkan penelitian yang telah dilaksanakan di laboratorium kampus 
Jurnal Sulolipu : Media Komunikasi Sivitas Akademika dan Masyarakat

Vol. 17 No.II 2017

e-issn : 2622-6960, p-issn : 0854-624X

kesehatan Makassar, dengan menggunakan zeolite alam dan batu apung sebagai bahan adsorben dalam upaya menurunkan kadar clorida yang terdapat dalam air payau/asin pada sumur gali di daerah pesisir Tanjung Bayam kota Makassar,yang menjadi lokasi pengambilan sampel dengan variasi dosis yang berbeda diperoleh hasil sebagai berikut.

Tabel 1

Rata-rata Hasil Penurunan Kadar Clorida Dengan Menggunakan Zeolit Dan Batu Apung Pada Air Payau Di Tanjung Bayam Kota Makassar Tahun 2017

\begin{tabular}{|c|c|c|c|c|c|c|}
\hline \multirow{2}{*}{$\begin{array}{l}\mathbf{N} \\
\mathbf{O}\end{array}$} & \multirow{2}{*}{$\begin{array}{c}\text { Dosis } \\
\text { Zeoit } \\
\text { dan } \\
\text { Batu } \\
\text { Apung } \\
(\mathrm{gr})\end{array}$} & \multicolumn{3}{|c|}{ Kadar Korida } & \multirow{2}{*}{$\begin{array}{l}\text { Rata- } \\
\text { rata }\end{array}$} & \multirow{2}{*}{$\begin{array}{c}\text { Penu } \\
\text { unan } \\
(\%)\end{array}$} \\
\hline & & I & II & III & & \\
\hline 1 & Awal & $\begin{array}{c}75 . \\
976 \\
, 44\end{array}$ & $\begin{array}{c}75.976 \\
, 44\end{array}$ & $\begin{array}{c}75.976 \\
, 44\end{array}$ & $\begin{array}{c}75.976 \\
, 44\end{array}$ & - \\
\hline 2 & 180 & $\begin{array}{c}43 . \\
486 \\
, 51\end{array}$ & $\begin{array}{c}43.986 \\
, 51\end{array}$ & $\begin{array}{c}37.488 \\
, 38\end{array}$ & $\begin{array}{c}43.319 \\
, 9\end{array}$ & $\begin{array}{c}42,98 \\
\%\end{array}$ \\
\hline 3 & 190 & $\begin{array}{c}39 . \\
987 \\
, 6\end{array}$ & $\begin{array}{c}38.488 \\
, 07\end{array}$ & $\begin{array}{c}37.488 \\
, 38\end{array}$ & $\begin{array}{c}38.654 \\
, 68\end{array}$ & $\begin{array}{c}49,12 \\
\%\end{array}$ \\
\hline 4 & 200 & $\begin{array}{c}35 . \\
988 \\
, 84\end{array}$ & $\begin{array}{c}32.489 \\
, 93\end{array}$ & $\begin{array}{c}35.988 \\
, 84\end{array}$ & $\begin{array}{c}34.822 \\
, 53\end{array}$ & $\begin{array}{c}54,16 \\
\%\end{array}$ \\
\hline
\end{tabular}

Berdasarkan tabel,dapat dikemukan hasil awal pada repikasi I sampai replikasi III kandungan clorida sebesar 75.976,44 $\mathrm{mg} / \mathrm{l}$,dengan nilai rata-rata penurunan kadar clorida sebelum melaui proses pengolahan sebesar 75.976,44 mg/l setelah melalui proses pengolahan I dengan dosis $180 \mathrm{gr}$ turun menjadi $43.486,51 \mathrm{mg} / \mathrm{l}$,pada pengolahan II turun menjadi 43.986,6 $\mathrm{mg} / \mathrm{l}$,dan pada pengolahan III turun menjadi 42.486,83 mg/l dengan rata-rata penurunan $43.319,9$ dengan persen,pada pengolahan I dengan dosis $190 \mathrm{gr}$ turun menjadi $39.987,6 \mathrm{mg} / \mathrm{l}$,pada pengolahan II turun menjadi $38.488,07 \mathrm{mg} / \mathrm{l}$ dan pada pengolahan ke III turun menjadi $37.488,38$ $\mathrm{mg} / \mathrm{l}$.Dengan rata-rata penurunan $38.654,8 \mathrm{mg} / \mathrm{l}$ dengan persen penurunan $\%$,dan pada berat 200 gr pada pengolahan I turun menjadi $35.988,84 \mathrm{mg} / \mathrm{l}$,pada pengolahan II turun menjadi $32.489,93 \mathrm{mg} / \mathrm{l}$ dan pada pengolahan ke III turun menjadi $35.88,84 \mathrm{mg} / /$ dengan ratarata penurunan sebesar $34.822,53 \mathrm{mg} / \mathrm{l}$ dengan penurunan $\mathrm{mg} / \mathrm{l}$ dengan persen penurunan $\%$.

\section{PEMBAHASAN}

Berdasarkan hasil awal pada repikasi I sampai replikasi III kandungan clorida sebesar 75.976,44 $\mathrm{mg} / \mathrm{l}$,dengan nilai rata-rata penurunan kadar clorida sebelum melaui proses pengolahan sebesar 75.976,44 mg/l setelah melalui proses pengolahan I dengan dosis $180 \mathrm{gr}$ turun menjadi 43.486,51 $\mathrm{mg} / \mathrm{l}, \mathrm{pada}$ pengolahan II turun menjadi 43.986,6 mg/l, dan pada pengolahan III turun menjadi $42.486,83 \mathrm{mg} / \mathrm{l}$ dengan rata-rata penurunan 43.319,9 dengan persen,pada pengolahan I dengan dosis $190 \mathrm{gr}$ turun menjadi 39.987,6 $\mathrm{mg} / \mathrm{l}$,pada pengolahan II turun menjadi $38.488,07 \mathrm{mg} / \mathrm{l}$ dan pada pengolahan ke III turun menjadi $37.488,38$ $\mathrm{mg} / \mathrm{l}$. Dengan rata-rata penurunan $38.654,8$ $\mathrm{mg} / \mathrm{l}$ dengan persen penurunan $\%$,dan pada berat 200 gr pada pengolahan I turun menjadi 35.988,84 mg/l,pada pengolahan II turun menjadi $32.489,93 \mathrm{mg} / \mathrm{l}$ dan pada pengolahan ke III turun menjadi $35.88,84 \mathrm{mg} / /$ dengan rata-rata penurunan sebesar $34.822,53 \mathrm{mg} / \mathrm{l}$ dengan penurunan $\mathrm{mg} / \mathrm{l}$ dengan persen penurunan $\%$.

Berdasarkan hasil penelitian dengan dosis 200 gram dimana table menunjukkan tingkat penurunan yang efektif dibandingkan dengan dosis 180,190. dimana kandungan awal clorida pada sampel air payau/asin sebesar 75,976,44 $\mathrm{mg} / \mathrm{l}$, setelah dilakukan proses pengolahan kadar clorida menurun hingga $35,988,84 \mathrm{mg} / \mathrm{l}$

\section{PENUTUP \\ Kesimpulan}

Berdasarkan hasil penelitian dan pembahasan,maka penulis dapat mengemukakan kesimpulan bahwa kadar klorida pada air payau dengan menggunakan media zeolite dan batu apung yaitu

1. Dosis $180 \mathrm{gr}$ rata-rata penurunan kadar klorida 43.319,9 mg/l,dengan presentase penurunan $42,98 \%$

2. Dosis $190 \mathrm{gr}$ rata-rata penurunan kadar klorida $38.654,68 \mathrm{mg} / \mathrm{l}$,dengan presentase penurunan $49,12 \%$

3. Dosis $200 \mathrm{gr}$ rata-rata penurunan kadar klorida $34.822,53 \mathrm{mg} / \mathrm{l}$ dengan presentase penurunan $54,16 \%$. 
Jurnal Sulolipu : Media Komunikasi Sivitas Akademika dan Masyarakat Vol. 17 No.II 2017

e-issn : 2622-6960, $p$-issn : 0854-624X

\section{Saran}

Berdasarkan hasil penelitian,maka penulis menyarankan hal-hal sebagai berikut :

1. Penelitian ini belum efektif sehingga dosis zeolite dan batu apung perlu ditambahkan sehingga dapat menurunkan kadar klorida lebih efektif.
2. Diharapkan bagi peneliti selanjutnya untuk meneliti lebih lanjut tentang kemampuan zeolite dan batu apung sebagai media filter air payau dengan metode up flow.

\section{DAFTAR PUSTAKA}

Astuti,Widi,dkk.2007.Desalinasi Air Payau Menggunakan SurfactantModified Zeolit (Smz). jurnal Zeolit indonesia. http://journals.itb.ac.id/index.php/jzi/article/viewFile/1698/993 di akses pada tanggal 30 januari 2017.

Budiyono,Sumardiono Siswo.2013. Tehnik pengolahanair.Yogyakarta: Graha IImu.

Depkes,Sulawesi

Selatan.2014.(online)

http//www.depkes go.id/resources/download/profil_Kes_Provinsi_2014/27_Sulawesi_Selatan_2014.pdf di akses pada tanggal 15 januari 2017

Fakhurroja,Hanif,2010. Membuat Sumur Air Di Berbagai Lahan. Bogor: Griya Kreasi.

Ign,Suharto. 2011. Limbah Kimia Dalam Pencemaran Udara Dan Air. Yogyakarta : Andi

Imam Bukhari,2013.Kemampuan Batu Apung Dalam Menurunkan Kadar Chlorida (Cl) Pada Air Payau/Asin.Makassar:Politeknik Kesehatan Makassar Jurusan Kesehatan Lingkungan.(KTI tidak diterbitkan)

Kusnaedi,2010. Mengolah Air Bersih Untuk Air Minum.Bogor:Penebar Swadaya.

Kusumahati.i.1999. Studi Kemampuan Resin Kation $\mathrm{Na}^{+}$dan $\mathrm{H}^{+}$sebagai media penukar ion untuk menurunkan kandungan tembaga.Program studi teknik lingkungan,ITS,Surabaya.

Noor,Muhammad.,2004.Lahan Rawa Sifat Dan Pengolahan Tanah Bermasalah Sulfat Masam.Jakarta:PT.Raja Grafindo Persada.

Rahayu,Iman.,2007.Cara Menangani Air Kotor Menjadi Air Bersih: Bandung:Citra Praya.

Sanropie.,Djasio,dkk,1984.Pedoman Bidang Studi Penyediaan Air Bersih Akedemi Penilik Kesehatan Teknologi Sanitasi,Jakarta:Pusat Pendidikan dan Latihan Pegawai Departemen Kesehatan RI.

Sutrisno, Totok., Eni Suciati., 2002. Teknologi Penyediaan Air Bersih. Jakarta : Rineka Cipta.

Teukujalal, 2015, (online) air bersih,http//teukujalal.wordpress.com/makalah_air_bersih/diakses pada tanggal 11 Jnuari 2017

Untung,Onny.,1995.Menjernihkan AirKotor.Jakarta:PT.Pustaka Pembangunan Swadaya Nusantara. 